Plant Tissue Cult. \& Biotech. 22(1): 41-50, 2012 (June)

$\overline{\text { PTC\&B }}$

\title{
Agrobacterium-mediated Genetic Transformation of Local Cultivars of Chickpea (Cicer arietinum L.)
}

\author{
Ripa Akter Sharmin'1, Jasmin Akter, R.H. Sarker* and M.I. Hoque
}

Plant Breeding and Biotechnology Laboratory, Department of Botany, University of

Dhaka, Dhaka-1000, Bangladesh

Key words: Chickpea, Transformation, GUS expression, nptII gene

\begin{abstract}
Agrobacterium-mediated genetic transformation protocol was established for two chickpea (Cicer arietinum L.) varieties, namely Barichhola-4 (Bch-4) and Barichhola-5 (Bch-5). Transformation ability of different explants such as decapitated embryo with single cotyledon disc (DEC), decapitated embryo (DE) and slice embryo decapitated at shoot end with single cotyledon disc (SEC) were tested using Agrobacterium tumefaciens strain LBA4404 harbouring binary plasmid pBI121, containing the GUS and nptII genes. Maximum transformation ability was exhibited by explants of decapitated embryo (DE) from Barichhola-5 (Bch-5). The optimum regeneration from the transformed tissue was achieved on MS supplemented with $0.5 \mathrm{mg} / \mathrm{l} \mathrm{BAP,} 0.5 \mathrm{mg} / \mathrm{l} \mathrm{Kn}$ and $0.2 \mathrm{mg} / \mathrm{l} \mathrm{NAA}$ along with double the amount of $\mathrm{CaCl}_{2}$ and $\mathrm{KNO}_{3}$. Selection of the transformed shoots was carried out by gradually increasing the concentration of kanamycin to $150 \mathrm{mg} / \mathrm{l}$. Stable expression of the GUS gene was detected in various parts of the transformed shoots through GUS histochemical assay. Stable integration of nptII gene within the genomic DNA from these transformed shoots was confirmed through PCR analysis.
\end{abstract}

\section{Introduction}

Chickpea (Cicer arietinum L.) is considered as an important pulse crop in the Indian subcontinent as far as the production and area under cultivation are concerned. Chickpea is valued for its nutritive seeds with high protein content of 25.3-28.9\% (Hulse 1991). Along with proteins it also provides a good proportion of carbohydrates, fats and minerals. In Bangladesh chickpea is ranked as the third most important pulse crop and it is considered as an important source of dietary protein both for human and animal. In addition, as a leguminous crop, it has the unique ability to improve the soil fertility by fixing atmospheric nitrogen symbiotically.

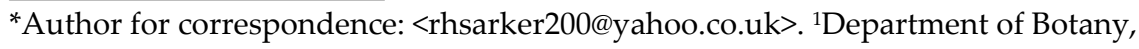
Jagannath University, Dhaka-1100, Bangladesh. 
A number of biotic and abiotic stresses severely affect the yield potential of this crop all over the world. Among the biotic stresses the disease caused by various fungi mostly affecting the productivity of this important grain legume. The main fungal diseases of chickpea are Botrytis gray mold caused by Botrytis cinerea, Fusarium wilt caused by Fusarium oxysporum and Ascochyta blight caused by Ascochyta rabiei. Moreover, the damage caused by a number of insect pests is also one of the main constraints which limit the production of chickpea. Pod-borer (Helicoverpa armigera and Heliothis sp.) has been reported to cause almost $80 \%$ of total damage of this crop in Bangladesh (Ahmed et al. 1982). Therefore, there is an urgent need to develop disease and pest resistant cultivars of chickpea and to increase the productivity in order to meet the growing need for this crop in Bangladesh.

Improvement in chickpea through conventional breeding is limited due to the lack of adequate and satisfactory levels of genetic variability within cultivated chickpea germplasm. Interspecific hybridization in chickpea has been largely unsuccessful (Ahmad et al. 1988) and the wild species did not respond well to introgression of genes through conventional breeding techniques for yield improvement (Van Rheenen et al. 1993).

Under these circumstances techniques of genetic transformation provide an unique opportunity in improving the agronomic performance of this grain legume crop. Agrobacterium-mediated transformation technique has been utilized in the past to generate variability in a number of leguminous crops including soybean (Hinchee et al. 1988), pea (Schroeder et al. 1993) and subterranean clover (Khan et al. 1994).

A few reports are also available on genetic transformation of chickpea (Fontana et al. 1993, Kar et al. 1996, Khishnamurthy et al. 2000, Sarmah et al. 2003, Polowick et al. 2004 and Tewari-Singh et al. 2004). These reports clearly demonstrated that Agrobacterium-mediated genetic transformation can be exploited in transforming various types of chickpea explants.

Following the above reports in the present investigation Agrobacteriummediated transformation was carried out using various explants from two varieties of chickpea (Barichhola-4 and Barichhola-5) growing in Bangladesh. Here, a simple protocol for multiple shoot regeneration from different explants following Agrobacterium-mediated gene transfer has been reported. Expression of the GUS gene was detected by histochemical assay and integration of nptll gene was confirmed through PCR analysis. 


\section{Materials and Methods}

Two varieties of chickpea (Cicer arietinum L.), namely Barichhola-4 (Bch-4) and Barichhola-5 (Bch-5) were used. Seeds of these two varieties of chickpea were collected from Bangladesh Agricultural Research Institute (BARI), Joydebpur, Gazipur.

A variety of embryo explants, namely decapitated embryo with single cotyledon disc (DEC), decapitated embryo (DE) and slice embryo decapitated at shoot end with single cotyledon disc (SEC) were used. These explants were collected from surface sterilized and overnight soaked seeds following the protocol described by Sarker et al. 2000. For shoot initiation and development MS supplemented with various combinations and concentrations of BAP, $\mathrm{Kn}$ and NAA were used. When required the MS macrosalts such as $\mathrm{CaCl}_{2}$ and $\mathrm{KNO}_{3}$ were used in higher concentrations than those are used in MS. All media had 3\% sucrose and $0.8 \%$ agar with $\mathrm{pH} 5.8$, adjusted before autoclaving. In vitro regenerated shoots were subcultured regularly to fresh medium at an interval of 12 - 15 days for further multiplication of shoots. For root induction MS supplemented with various concentrations of IBA was used. Cultures were maintained under $16 \mathrm{hr}$ photoperiod at $25 \pm 2^{\circ} \mathrm{C}$. The plantlets with sufficient number of roots were transplanted to small pots containing sterilized soil for their establishment.

Agrobacterium tumefaciens strain LBA4404 harbouring the binary plasmid pBI121 conferring ß-glucuronidase (GUS) and nptII gene was used for transformation.

The excised explants were incubated in the Agrobacterium suspension for 30 min. The explants were then soaked on a sterilized Whatman filter paper to remove the bacterial suspension and co-cultured on MS supplemented with 0.5 $\mathrm{mg} / \mathrm{l} \mathrm{BAP}, 0.5 \mathrm{mg} / \mathrm{l} \mathrm{Kn}$ and $0.2 \mathrm{mg} / \mathrm{l} \mathrm{NAA}$ along with double the amount of $\mathrm{CaCl}_{2}$ and $\mathrm{KNO}_{3}$ as generally used in MS for three days in the dark. Following coculture the explants were washed several times with sterile distilled water. The infected explants were finally washed with $300 \mathrm{mg} / \mathrm{l}$ ticarcillin (Duchefa, Netherlands). After soaking on a sterile Whatman filter paper they were subcultured on the regeneration medium with $50 \mathrm{mg} / \mathrm{l}$ combactum (Pfizer, Germany) and $50 \mathrm{mg} / \mathrm{l}$ ticarcillin to control the over growth of bacteria. The infected explants were then placed in the growth room for regeneration under $16 / 8 \mathrm{hrs}$ light/dark cycle at $25 \pm 2^{\circ} \mathrm{C}$.

To select transformed tissues, the regenerating explants were subcultured on a fresh regeneration medium with $50 \mathrm{mg} / \mathrm{l}$ kanamycin after three weeks of initial culture. The selected antibiotic was increased with each subculture at 14 days intervals up to $150 \mathrm{mg} / \mathrm{l}$ kanamycin. During each subculture the dead and deep 
brown tissues were discarded and green shoots and shoot buds were subcultured to fresh medium containing the next higher concentration of kanamycin. Transformation ability of explants was monitored by GUS histochemical assay (Jefferson et al. 1987) by submerging them in the substrate X-gluc (5- bromo, 4-chloro, 3-indolyl $\alpha$-D-glucuronide) and incubating them at $37^{\circ} \mathrm{C}$ for two-three days. They were then washed in $70 \%$ alcohol and scored for GUS expression.

The integration of the nptII gene in the chickpea was analysed by PCR. Genomic DNA was isolated from both transformed and nontransformed chickpea shoots. CTAB method (Doyle and Doyle 1990) was used for DNA isolation. For the detection of the nptII coding sequence, DNA was subjected to PCR using the following primers and conditions: forward 5'-TAG CTT CTT GGG TAT CTT TAA ATA-3' and reverse 5'-CCA GTT ACC TTC GGA AAA AGA GTT-3'. For nptII gene the cycling conditions were $5 \mathrm{~min}$ at $94^{\circ} \mathrm{C}$ denaturation and 30 amplification cycles using $94^{\circ} \mathrm{C}$ for $1 \mathrm{~min}, 55^{\circ} \mathrm{C}$ for $1 \mathrm{~min}$ (annealing) and $72^{\circ} \mathrm{C}$ for $1 \mathrm{~min}$ followed by $5 \mathrm{~min}$ at $72^{\circ} \mathrm{C}$. The amplified DNA was run on $0.80 \%$ agarose gel and stained with ethidium bromide $(0.05 \mu \mathrm{l} / \mathrm{ml})$.

\section{Results and Discussion}

Development of an in vitro regeneration system is an essential task before embarking upon a research project on genetic transformation of any particular crop. In the present investigation in vitro regeneration experiments were carried out using different explants following the report of Sarker et al. (2005) with slight modification. Results of in vitro regeneration from various explants of two varieties of chickpea using MS supplemented with different combinations and concentrations of BAP, NAA and Kn are presented in Table 1. It was observed that healthy and green shoots with expanded leaves were regenerated from decapitated embryo with single cotyledon disc (DEC) from both the varieties on MS supplemented with $0.5 \mathrm{mg} / \mathrm{l} \mathrm{BAP,} 0.5 \mathrm{mg} / \mathrm{l} \mathrm{Kn}$ and $0.2 \mathrm{mg} / \mathrm{l} \mathrm{NAA}$ along with double the amount of $\mathrm{CaCl}_{2}$ and $\mathrm{KNO}_{3}$ used in MS. It was observed that variable number of shoots can be regenerated from different explants on the medium containing the hormonal supplements of with $0.5 \mathrm{mg} / \mathrm{l} \mathrm{BAP,} 0.5 \mathrm{mg} / 1 \mathrm{Kn}$ and 0.2 mg/l NAA without the supplements of additional $\mathrm{CaCl}_{2}$ and $\mathrm{KNO}_{3}$ (Table 1). The second highest regeneration responses were obtained from DE explants. But in most of the cases necrosis was found to occur on the tip of these regenerated shoots and such shoots failed to grow and survive further. To overcome this problem of shoot tip necrosis in chickpea double the concentration of $\mathrm{CaCl}_{2}$ and $\mathrm{KNO}_{3}$ used in $\mathrm{MS}$ was added in the regeneration medium following the report of Ye et al. (2002) as they could overcome shoot tip death in lentil. 
Agrobacterium-mediated Genetic Transformation

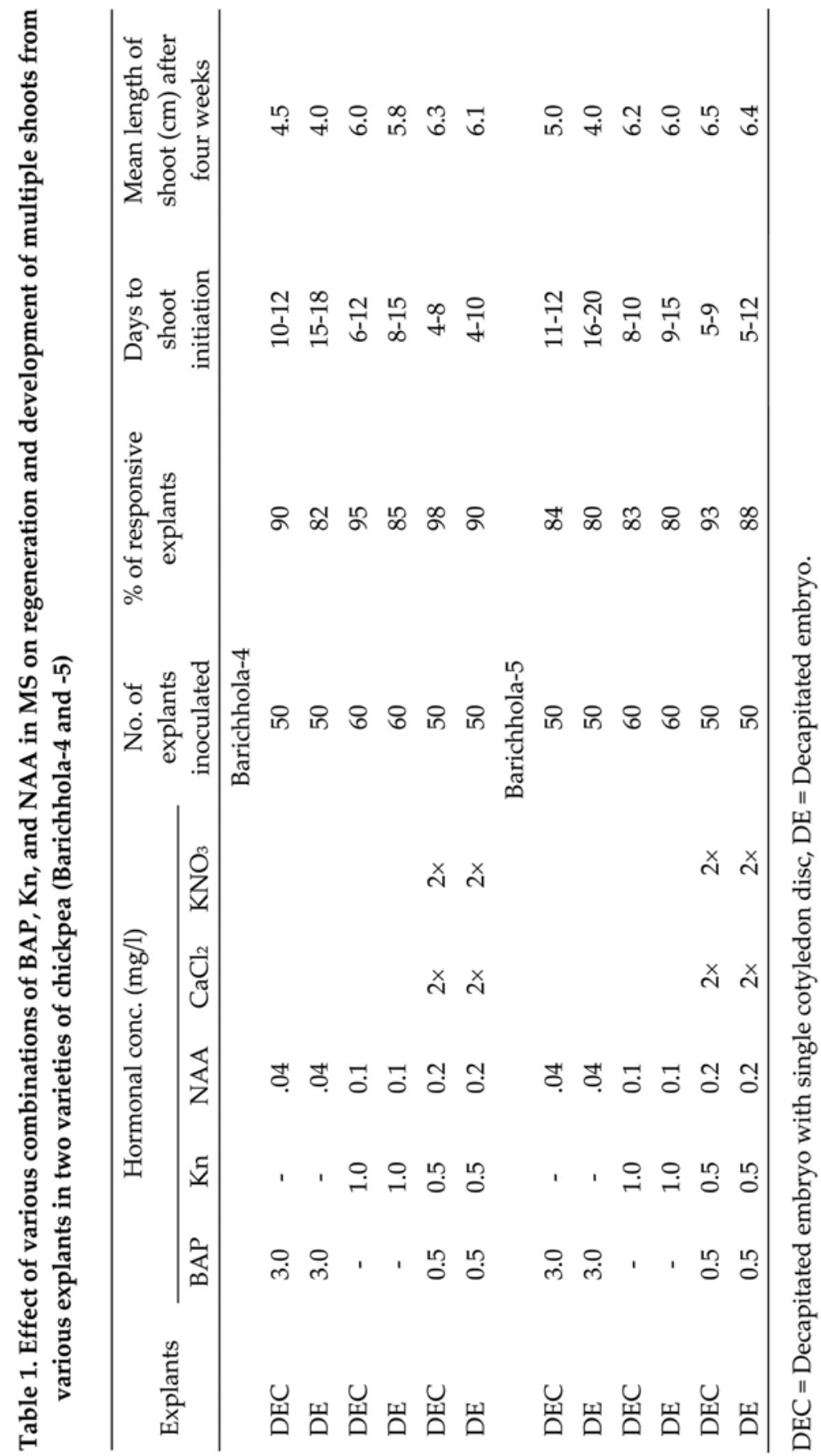


Best root induction at the base of the in vitro regenerated shoots was achieved on MS supplemented with $0.2 \mathrm{mg} / \mathrm{l} \mathrm{IBA}$. However, previous workers (Fontana et al. 1993, Jayanand et al. 2003, Fratini and Ruitz 2003) obtained good root induction when shoots were regenerated on MS containing Kn.

The second part of the present investigation was confined to the development of an Agrobacterium-mediated genetic transformation in two varieties of chickpea using three types of explants, namely decapitated embryo (DE), decapitated embryo with single cotyledon disc (DEC) and slice embryo decapitated at shoot end with single cotyledon disc (SEC). Transformation ability of these various explants was studied through histochemical GUS assay following the methods of Jefferson (1987). Among the different explants, decapitated embryo (DE) from both varieties of chickpea (Bch-4 and Bch-5) showed high transient GUS expression as confirmed by GUS histochemical assay following their infection with strain LBA4404 of Agrobacterium tumefaciens (Table 2). In most of the GUS positive explants conspicuous blue color was observed at the cut surface of these explants. In some of the cases the whole explants exhibited the characteristic blue colour due to expression of GUS gene (Fig. 1a-c).

Several factors influencing Agrobacterium-mediated genetic transformation, namely optical density of bacterial suspension, incubation period, and co-cultivation period were optimized during present study. Transformation efficiency of explants, in both varieties was found maximum when optical density of bacterial suspension was 1.0 at $600 \mathrm{~nm}, 30 \mathrm{~min}$ of incubation period and three days of cocultivation period. In chickpea Krishnamurthy et al. (2000) incubated mature embryo explants for $20 \mathrm{~min}$ and then co-cultivated for 3 days during transformation, while Tewari-Singh et al. (2004) employed the same co-cultivation periods but they incubated explants in bacterial suspension for 1 - $2 \mathrm{hrs}$. In the present study it was observed that a longer infection and co-cultivation period enhanced over growth of bacteria in culture medium, thereby hampering proper growth of infected explants.

Following co-cultivation the explants were transferred to regeneration medium in obtaining regeneration of shoots through organogenesis. The best responses of shoot regeneration was observed from co-cultivated decapitated embryo (DE) from both the varieties on MS supplemented with $0.5 \mathrm{mg} / \mathrm{l} \mathrm{BAP \text {, }}$ $0.5 \mathrm{mg} / \mathrm{Kn}$ and $0.2 \mathrm{mg} / \mathrm{l} \mathrm{NAA}$ along with double the amount of $\mathrm{CaCl}_{2}$ and $\mathrm{KNO}_{3}$ used in MS.

Since the Agrobacterium tumefaciens strain LBA4404 has nptII gene and it confers kanamycin resistance, therefore the selection of the transformants was carried out using various concentrations of kanamycin. In the present study, cocultivated explants were cultured initially in a medium without selection 
pressure of kanamycin. Following initiation of regeneration about $2.0 \mathrm{~cm}$ long shoots were transferred to the selection media. In chickpea, Tewari-Singh et al. (2004) applied selection pressure after culturing the explants in selection free regeneration medium for 3 weeks. It was noticed that a preculture period and a delayed selection using kanamycin was useful in obtaining regeneration with high transformation frequency (McHughen et al. 1989, Sarker et al. 2000).
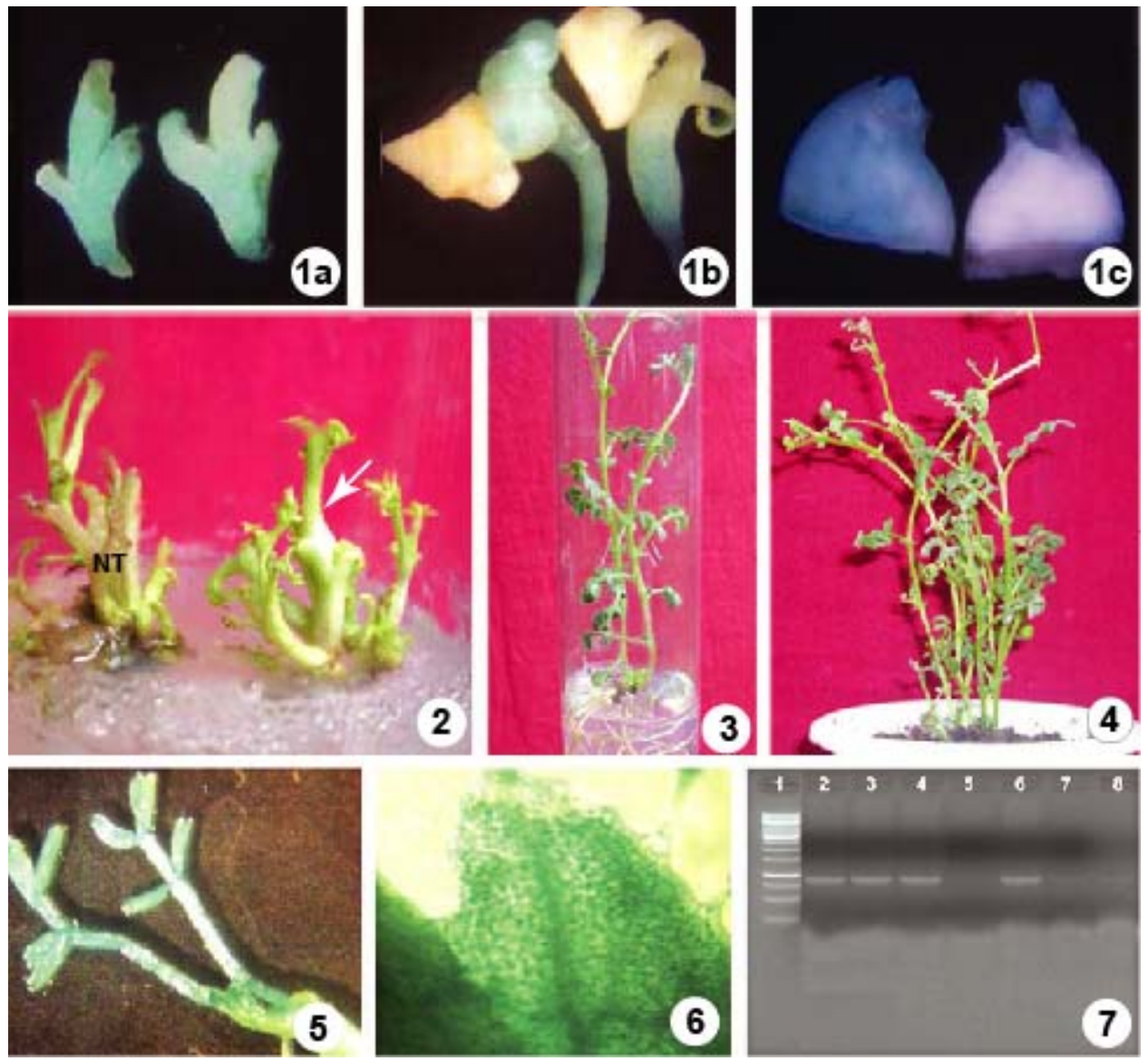

Figs 1 - 7: Transformation of chickpea using GUS and nptII gene. 1. Histochemical localization of GUS activity at the cut ends of DE explant (a), SEC (b) and DEC (c) of Bch-5 variety. 2. Putatively transformed shoot (arrow) of Bch-5 survived on the selection medium containing $150 \mathrm{mg} / 1$ kanamycin . Note that the non transformed shoot (NT) became brown. 3. Fully developed roots at the base of regenerated transformed shoots of Bch-5. 4. Putatively transformed plantlets $\left(\mathrm{T}_{0}\right)$ transferred to soil. 5. A part of a shoot from a transformed plantlet showing stable expression of GUS gene in case of Bch-5. 6. Magnified view of young leaf from transformed plantlets (Bch-5) showing the presence of blue colour following GUS assay (x 8) 7. PCR amplification of transformed shoots for nptII gene (lane-1: $1 \mathrm{~kb}$ ladder; lanes 2, 3, 4 and 6: transformed plantlets showing the amplification of nptII gene; lane -7: non-transformed plantlet; lane-8: water control. 
In the present study, the initial selection pressure was $50 \mathrm{mg} / \mathrm{l} \mathrm{kanamycin}$ and it was increased gradually in subsequent subcultures. It was observed that all control shoots died in the selection medium having $150 \mathrm{mg} / \mathrm{l} \mathrm{kanamycin.} \mathrm{To}$ screen the transformed shoot more effectively, higher concentrations of selective agents were applied. Krishnamurthy et al. (2000) applied $100 \mathrm{mg} / \mathrm{l}$ and TewariSingh et al. (2004) applied $250 \mathrm{mg} / \mathrm{l}$ of kanamycin, respectively as a final selection pressure. But in the present investigation, it was found that selection medium containing $150 \mathrm{mg} / \mathrm{l}$ kanamycin was sufficient to select transformed shoots (Fig. 2).

Shoots those survived kanamycin selection were cultured on MS supplemented with $0.2 \mathrm{mg} / \mathrm{l} \mathrm{IBA}$ without kanamycin to induce roots (Fig. 3). After the development of sufficient roots, the plantlets were transplanted to soil (Fig. 4). Histochemical localization of GUS expression was also carried out with the fully developed plantlets growing in soil. Conspicuous blue color was observed in leaves of such plantlets that indicates the stable integration of GUS gene (Figs 5 and 6).

The transformation experiment indicates that, decapitated embryo explant was found to be the most suitable for transformation of chickpea. Shoots of Barichhola-5 showed better survibility in selection medium when it was infected with Agrobacterium tumefaciens strain LBA4404 (Table 2).

Table 2. Response of different explants from two chickpea varieties towards transformation with Agrobacterium strain analyzed by transient GUS histochemical assay.

\begin{tabular}{|c|c|c|c|c|c|c|c|}
\hline \multirow[t]{2}{*}{ Varieties } & \multirow{2}{*}{$\begin{array}{l}\text { No. of explants } \\
\text { assayed for } \\
\text { GUS expression }\end{array}$} & \multicolumn{3}{|c|}{$\begin{array}{c}\text { No. of GUS +ve } \\
\text { explants }\end{array}$} & \multicolumn{3}{|c|}{$\begin{array}{l}\% \text { of GUS +ve } \\
\text { explants }\end{array}$} \\
\hline & & DE & DEC & SEC & $\mathrm{DE}$ & DEC & SEC \\
\hline Barichhola-4 & 30 & 22 & 11 & 20 & 73.33 & 36.66 & 66.66 \\
\hline Barichhola-5 & 30 & 25 & 12 & 22 & 83.33 & 40 & 73.33 \\
\hline
\end{tabular}

$\mathrm{DEC}=$ Decapitated embryo with single cotyledon disc, $\mathrm{DE}=$ Decapitated embryo, $\mathrm{SEC}=$ slice embryo decapitated at shoot end with single cotyledon disc.

The transgenic nature of the shoots was confirmed by PCR amplification of the nptII gene present within the genomic DNA of 5 randomly selected putatively transformed plantlets (Fig. 7). Specific primers were used for this purpose as mentioned in the Materials and Methods. Such observation primarily indicates the presence of transgenes within the DNA of the host plant shoots.

Agrobacterium-mediated genetic transformation protocol developed through the present investigation may be used to incorporate the useful candidate genes conferring resistance against disease, insect and pest in the chickpea varieties grown in Bangladesh. 
Agrobacterium-mediated Genetic Transformation

\section{Acknowledgements}

This study was supported by the United States Department of Agriculture (USDA) through a project "Improvement of Grain Legumes through Transformation". Authors are thankful to BARI authorities for providing chickpea seeds for this investigation.

\section{References}

Ahmad F, Slinkard AE and Scoles GJ (1988) Investigations into the barrier(s) to interspecific hybridization between Cicer arietinum L. and eight other annual Cicer species. Plant Breed. 100: 192-198.

Ahmed HU, Baker MA and Alam KB (1982) Disease survey of major winter and summer plulses in Bangladesh. In: Proc. of the Workshop on Pulses, 18-19 Aug. 1981, Bangladesh Agricultural Research Institute. pp. 257-264.

Doyle JJ and Doyle JL (1990) Isolation of plant DNA from fresh tissue. Focus 12: 13-15.

Fratini R and Ruitz ML (2003) A rooting procedure for lentil and other hypogeous legumes (pea, chickpea and Lathyrus) based on explant polarity. Plant Cell. Rep. 21: 726-732.

Fontana GS, Santini L, Caretto S, Frugis G and Mariotti D (1993) Genetic transformation in the grain legume Cicer arietinum L. (Chickpea). Plant Cell Rep. 12: 194-198.

Hinchee MAW, Connor-Ward DV, Newell CA, McDonell RE, Sato SJ, Gasser CS, Fischhoff DA, Re DR, Fraley RT and Horsch RB (1988). Production of transgenic soyabean plants using Agrobacterium-mediated DNA transfer. Biotechnology 6: 915922.

Hulse JH (1991) Nature, composition and utilization of grain legumes. p. 11-27. In: Uses of tropical legumes: Proceedings of a Consultants' Meeting, 27-30 March 1989, ICRISAT Center. ICRISAT, Patancheru, A.P. 502 324, India.

Jayanand B, Sudarsanam G and Sharma KK (2003) An efficient protocol for the regeneration of whole plants of chickpea (Cicer arietinum L.) by using axillary meristem explants derived from in vitro germinated seedlings. In vitro Cell Dev. Biol. Plant. 39: 171-179.

Jefferson RA, Kavanagh TA and Bevan MW (1987) GUS fusion: -glucuronidase as a sensitive and versatile gene fusion marker in high plants. EMBO J. 6: 3901-3907.

Kar S, Johnson TM, Nayak P and Sen SK (1996) Efficient transgenic plant regeneration through Agrobacterium-mediated transformation of chickpea (Cicer arietinum L.). Plant Cell Rep. 16: 32-37.

Khan MRI, Tabe LM, Heath LC, Spencer D and Higgins TJV (1994). Agrobacteriummediated genetic transformation of subterranean clover (Trifolium subterrancum L.). Plant Physiol. 105(2): 81-88.

Krishnamurthy KV, Suhasini K, Sagare AP, Meixner M, Kathen A, Pickardt T and Schieder O (2000) Agrobacterium-mediated transformation of chickpea (Cicer arietinum L.) embryo axes. Plant Cell Rep. 19: 235-240. 
McHughen A, Jordan M and Feist G (1989) A preculture period prior to Agrobacterium inoculation increases production of transgenic plants. J. Plant Physiol. 135: 245-248.

Polowick PL, Baliski DS and Mahon JD (2004) Agrobacterium tumefaciens-mediated transformation of chickpea (Cicer arietinum L.): Gene integration, expression and inheritance. Plant Cell Rep. 23: 485-491.

Sarker RH, Ferdous T and Hoque MI (2005) In vitro Direct Regeneration of Three Indigenous Chickpea (Cicer arietinum L.) Varieties of Bangladesh. Plant Tissue Cult. \& Biotech. 15(2): 135-144.

Sarker RH, Islam MN, Islam A and Seraj ZI (2000) Agrobacterium-mediated genetic transformation of peanut (Arachis hypogea L.). Plant Tissue Cult. 10(2): 137-142.

Sarmah BK, Moore A and Tate A (2004) Transgenic chickpea seeds expressiong high levels of a bean-masylase inhibitor. Plant Cell Reports. 22: 586-599.

Schroeder HE, Schotz AH, Wardley-Richardson T, Spencer D and Higgins TJV (1993) Transformation and regeneration of two cultivars of pea (Pisum sativum L.). Plant Physiol. 101: 751-757.

Tewari-Singh N, Sen J, Kiesecker H, Reddy VS, Jacobsen HJ and Guha-Mukherje S (2004) Use of a herbicide or lysine plus threonine for non-antibiotic selection of transgenic chickpea. Plant Cell Rep. 22: 576-83.

Van Rheenen HA, Pundir RPS and Miranda JH (1993) How to accelerate the genetic improvement of a recalcitrant crop species such as chickpea. Cur. Sic. 65: 414-417.

Ye G, Menell DL, Conner AJ and Hill GD (2002) Multiple shoot formation in lentil (Lens culinaris) seeds. New Zealand J. Crop. and Hort. Sci. 30: 1-8. 